\title{
Logics in social media news making: how social media editors marry the Facebook logic with journalistic standards
}

\author{
Lischka, Juliane A
}

\begin{abstract}
News decisions of social media editors shape the news supply on social media channels such as Facebook. This study assesses based on qualitative interviews and a quantitative survey of social media editors in two social-media-savvy European countries, Finland and Switzerland, how Facebook's News Feed algorithm, Facebook users, journalistic standards, and the news brand determine social media news making. Results show that social media editors evaluate the news factors emotions and surprise as more important for Facebook news than for online news. Social media editors accentuate emotional and surprising story elements in a post to comply with user preferences and the logic of the News Feed algorithm. Thus, news values and news editing have become more user engagement driven. Yet traditional journalistic standards and the news brand characteristics set boundaries to a heavy user engagement orientation. Social media editors estimate that their outlet's news supply on Facebook is higher for entertaining news and lower for foreign politics and economic news stories. But they strive for a "good mix" of news adhering to both the Facebook logic and professional journalistic standards.
\end{abstract}

DOI: https://doi.org/10.1177/1464884918788472

Posted at the Zurich Open Repository and Archive, University of Zurich ZORA URL: https://doi.org/10.5167/uzh-162952

Journal Article

Accepted Version

Originally published at:

Lischka, Juliane A (2018). Logics in social media news making: how social media editors marry the Facebook logic with journalistic standards. Journalism:online.

DOI: https://doi.org/10.1177/1464884918788472 


\title{
Logics in Social Media News Making
}

\section{How social media editors marry the Facebook logic with journalistic standards}

\author{
Juliane A. Lischka
}

IKMZ - Department of Communication and Media Research

\author{
Andreasstrasse 15 \\ CH-8050 Zurich \\ Tel. +41(0)446352075 \\ j.lischka@ikmz.uzh.ch
}

\begin{abstract}
News decisions of social media editors shape the news supply on social media channels such as Facebook. This study assesses based on qualitative interviews and a quantitative survey of social media editors in two social-media-savvy European countries, Finland and Switzerland, how Facebook's News Feed algorithm, Facebook users, journalistic standards, and the news brand determine social media news making. Results show that social media editors evaluate the news factors emotions and surprise as more important for Facebook news than for online news. Social media editors accentuate emotional and surprising story elements in a post to comply with user preferences and the logic of the News Feed algorithm. Thus, news values and news editing have become more user engagement driven. Yet traditional journalistic standards and the news brand characteristics set boundaries to a heavy user engagement orientation. Social media editors estimate that their outlet's news supply on Facebook is higher for entertaining
\end{abstract}


news and lower for foreign politics and economic news stories. But they strive for a "good mix" of news adhering to both the Facebook logic and professional journalistic standards.

\section{Keywords}

Algorithm; Audience/Engagement; Facebook; News media; News values; Online/Digital Journalism; Social Media

\section{Introduction}

Social media channels, especially Facebook, have become relevant for news media as a distribution channel that accounts for additional traffic on the news outlets' websites. To track user engagement has become more important for news outlets over time (Cherubini and Nielsen, 2016), and such reader metrics influence news making practice (Karlsson and Clerwall, 2013; Vu, 2014). Yet user engagement on social media is determined by algorithms that curate content according to user preferences. The operating modes of social media algorithms that select individual content for users are at most indirectly observable and seem to differ from traditional journalistic standards (DeVito, 2017).

As one consequence, professional standards may adjust. Dimitrov (2014) expects that social media shapes the profession of journalism as new conventions develop, especially among social media enthusiastic journalists (Hedman and Djerf-Pierre, 2013). As a second consequence, news content may adapt. Content analyses have shown that 
news adapts to user preferences, leading to an increase in soft news in Facebook posts of German news outlets (Lischka and Werning, 2017; Steiner, 2016). However, longestablished journalistic news making standards are quite rigid to change (Ryfe, 2009). On an organizational level, the news brand identity also shapes newsroom standards and restrains fundamental changes in news making (Siegert et al., 2011).

This study conceptualizes the news brand and journalistic standards as a counterweight to the focus on user engagement in the algorithmic environment of Facebook. The research question is, how do considerations about Facebook's News Feed algorithm and users, journalistic standards, and the news brand determine the news making of social media editors? The goal is to understand how effectively the logics of social networks change news making conventions and, ultimately, news content posted on social networks.

Empirically, expert interviews followed by an online survey with social media editors of print, online-only, and public-service news outlets in Switzerland and Finland are conducted. The country selection follows a most similar systems design regarding journalistic professionalism and social media use of the population.

\section{Social media algorithms and social media news making}

Social media platforms strive to provide individualized content that attracts audiences to their sites, for which recommender systems are implemented. According to 
Facebook Inc (2015: 5), the News Feed Algorithm ensures that users remain and engage on the platform as the "top priority is to build useful and engaging products that enable people to connect and share."

Because recommender algorithms automatically preselect and assign relevance to posts but one cannot directly detect how they operate, news outlets lose some control over the distribution of news. Based on publicly available Facebook documents such as SEC (Securities and Exchange Commission) filings, patents, and press releases, DeVito (2017) reproduces the operating modes of the News Feed algorithm. Algorithm selection criteria include a user dimension (friend relationships, user interest, and engagement) and a post dimension (post age and content quality). For journalists, often observing the user engagement is one way for learning about the algorithm. Craig and Yousuf (2013) describe that understanding user behavior is essential for effective social media news making, indicating a close connection between user engagement and news editing. Groot Kormelink and Costera Meijer (2014: 167) argue that user-engaging storytelling formats are preferred to factual news reports on social media because "the audience demands good storytelling." Also, editors prefer to post such content on social media that affects as many users as possible to maximize engagement (Neuberger et al., 2014: 53). Lischka and Werning (2017) show an up to $20 \%$ higher share of human-interest topics in the Facebook posts compared to the print editions of German regional news outlets at the expense of hard news. Overall, these studies suggest an adjustment of standards of news making for social media news that results in a change of social media news supply. 


\section{The news brand and social media news making}

News outlets can also be regarded as brands (Chan-Olmsted, 2011; Krebs and Lischka, 2017; Lischka et al., 2018). A news brand sums up what a news outlet stands for and signals specific characteristics to audience members, staff, and other stakeholders (McManus, 1994). Both, the news brand and journalistic standards are linked value systems that journalists use as orientation for their work (Sylvie, 2007). The news brand identity, which is the corporate definition of the news brand, functions similarly to a corporate or newsroom culture as it guides and reinforces socialization of journalists in the newsroom, editorial decisions, and journalistic standards (Gravengaard and Rimestad, 2014; Siegert et al., 2011). The news brand identity serves as a heuristic for journalists and defines how news is processed and edited, including "background coverage and comments, the nature of the language used, and the treatment of visual images" (Siegert et al., 2011: 58). Therefore, the news brand affects news making and is reflected in its news content.

The news brand identity is determined by its political, social, regulative, technological, and competitive environments (Siegert et al., 2011). With social media platforms, the technological and competitive environments have changed for news outlets, which can affect the news brand identity as well as working standards and procedures, and, therefore, news content. Various studies have shown that professional journalistic 
culture, to which the news brand identity is related, is hard to change, whereas journalists agree that there is a need for change in news making for digital audiences (Ekdale et al., 2015; Gade, 2004; Ryfe, 2009). Chan-Olmsted (2011) emphasizes that social media content needs to be monitored to ensure consistency with the news brand. However, the reverse question is addressed in this article, which is, whether the news brand identity changes according to shifts in the social media environment, and with it editorial standards and practice.

\section{Journalistic standards and social media news making}

Previous research suggests that there are differences in journalistic standards for traditional and social media journalism. Journalists who regularly use social media think that the traditional roles of journalism must be reconsidered in contrast to journalists using social media less often (Hedman and Djerf-Pierre, 2013: 380). Craig and Yousuf (2013) investigate what social media editors consider as excellent journalism on social media, which is the "adherence to traditional accuracy standards with recognition of a new environment," which suggests "sophistication in engagement $[\ldots]$ and adding value by being human." That is, traditional standards also hold in the social media era, whereas engagement and adding a human touch are novel aspects in news making. According to Scacco et al. (2015), audience engagement and outreach have become part of journalists' digital gatekeeping roles. This can be seen as an indicator for the greater user orientation 
of journalists as reported by Andersson and Wadbring (2015). Similarly, as younger and digital-native generations of journalists get into the profession, a digital divide among journalists may enhance such norm shifts (Gillis and Johnson, 2015; Hedman and DjerfPierre, 2013).

Previous research also suggests that journalistic news factors and news values change in the social-network era. Gade (2004) reports that news values become more reader-driven in digital environments. Because of their specific experience with social media user behavior, Wasike (2013: 20) suspects that social media editors may hold unique news values. Usher (2014) shows that the news factors of immediacy, interactivity, and participation have emerged in the social media age. With DeVito (2017: 767), such changes are caused by the fundamental difference of the News Feed's algorithmic values from journalistic news factors. Whereas traditional news factors relate to deviance and social impact of a story, the News Feed algorithm merely considers personal significance.

Several studies assess the relation between traditional news factors and user engagement. According to Weber (2014), audience commenting, which is one form of user engagement, is enhanced by geographical proximity, impact on social groups, and controversy. In contrast, the power of a protagonist and facticity lower user engagement. In order to "please" an engagement-rewarding social media algorithm, Berger and Milkman's (2012) and Tenenboim and Cohen's (2015) results suggest that conflict, prominence, and emotions are effective. For surprise, previous studies reveal conflicting results. Whereas Tenenboim and Cohen (2015) and Weber (2014) report that surprise is 
not related to interactivity, Berger and Milkman (2012) find surprise related to news sharing. Social media posts containing opinions as opposed to pure factual reporting should be more relevant for users, as suggested by Weber (2014). Thus, if social media editors strive to maximize user engagement, they should value engagement-triggering news factors higher.

Overall, previous studies propose that there are rigid and adaptable elements in professional news making. Journalists who post social media news may select and edit news according to social media appropriate news values in compliance with the logic of the content curating social media algorithm, depending on their strategic social media goals. However, there may be news brand and cultural components that remain immutable to external influence. The following research questions are asked:

RQ 1. What are the strategic functions of their social media profiles for news outlets?

RQ 2. Which roles do Facebook's News Feed algorithm and Facebook users play for news making of social media editors?

RQ 3. Which roles do the news brand and journalistic standards play for news making of social media editors?

RQ 4. How do social media editors evaluate traditional news factors?

RQ 5. How does social media news content differ from the news content on a news outlet's website? 


\section{Method}

\section{Country selection}

This study focuses on Switzerland and Finland, which are two small European media markets with a solid public broadcasting and newspaper tradition, in addition to a clear separation between the tabloids and the quality press. In both countries, news information has been traditionally spread by daily newspapers and public service television news (Hallin and Mancini, 2004). Both countries have a professional journalism culture (Brüggemann et al., 2014). About half of the Finnish and Swiss population use social media (Bundesamt für Statistik, 2014; Statistics Finland, 2014). In Switzerland, the share of Twitter users is higher than in Finland (18\% and 6\%, respectively), whereas Facebook is similarly popular (43\%) (Latzer et al., 2013; Nummela, no year). For about one online news user in four, social media is most common for news access in both countries (Newman et al., 2016: 93). Hence, the countries have similar market conditions for social media news making. The country selection thus follows a similar systems design.

\section{Study 1: Interviews}

First, qualitative expert interviews were conducted with social media editors, who are in charge of posting on the social media accounts at national news outlets (Finland) 
and news outlets in the German-speaking area (Switzerland) that focus on hard news and have a significant reach in each country according to Newman et al. (2016), but vary in revenue model and newspaper legacy. In Finland, the hard-news outlets with the greatest reach include the public service broadcaster (PSB) Yle news, followed by Helsingin Sanomat online with a newspaper legacy, and the pure player Taloussanomat.fi (which focuses on business and financial news). The Swiss news outlets are the PSB news show SRF News, NZZ.ch with a newspaper legacy, and the pure player Watson (which targets to a young audience).

The interview guide examined information about the individual social media editor (job title, background, and responsibilities), newsroom organization, social media strategy and goals (e.g., to gain new users, enable audience engagement, and to get traffic on the news outlet's website, see Neuberger et al., 2014). The second part addressed the selection, editing, and posting process for social media news, differences between online and social media news, and the functions of social media algorithms. Social media editors were asked to discuss news factors for social media posts. These news factors included background and opinions (Weber, 2014), conflict/controversy (Tenenboim and Cohen, 2015; Weber, 2014), criminality (Tenenboim and Cohen, 2015), damage or negative consequences (Tenenboim and Cohen, 2015; Weber, 2014), emotions (Berger and Milkman, 2012), facts (Weber, 2014), impact on many groups within society (Weber, 2014), power of the main person (Weber, 2014), prominence (Tenenboim and Cohen, 2015), proximity, i.e., involvement of own nation (Weber, 2014), success or positive 
consequences (Weber, 2014), and surprise or unexpectedness (Berger and Milkman, 2012). The roles of journalistic professional standards and the news brand were asked. Logics of social media recommender algorithms were discussed as the final topic.

The interviews lasted between 45 and 60 minutes and were either face-to-face (Switzerland) or on Skype (Finland). The interviews with Swiss editors were in German, while the interviews with Finnish editors were in English. Job titles of the six interviewees were social media editor or social media manager.

Interview analysis followed a qualitative, descriptive approach. The interviews were transcribed to qualitatively code the answers for each interviewee to inform the research questions.

\section{Study 2: Online survey}

To quantify interview results based on a greater sample of social media editors and news outlets, an online survey was conducted in November and December 2017. For the online survey, 42 (Finland) and 50 (Switzerland) social media editors and online journalists with social media affinity for national and regional news outlets were collected through keyword searches (social media AND [journalist OR editor]) on LinkedIn, Twitter, and Facebook. An additional eight Finnish and eight Swiss contacts were suggested by these initially researched contacts. Since there are no external sources to estimate the total size of the social media editor population, a possible margin of error 
could not be estimated. Yet due to the extensive search, the author presumes that there should not be many more social media managers in high-reach news outlets in both countries that were not invited to the survey.

Invitations were sent via email or, if no email address was obtained, LinkedIn mail or Twitter direct message to 50 (Finland, of which 27 were from Yle) and 58 (Switzerland) contacts. The invitation was followed by up to two reminders. Of these contacts, 15 respondents from Finland and 22 from Switzerland completed the questionnaire, resulting in a return rate of $30 \%$ for Finland and $38 \%$ for Switzerland. Surveyed social media editors evaluated their social media proficiency and the frequency of posting news content on social media. Two of the Swiss respondents had no social media posting responsibilities and thus were excluded from the analysis, resulting in a total of $n=35$ valid responses.

The questionnaire was developed based on the interview findings and previous research and asked about the importance of various social media channels for the news outlet that the social media editor works for, the strategic goals that the social media channels fulfil (Neuberger et al., 2014), audience metrics that are observed (Cherubini and Nielsen, 2016), the selection process, and the editing process for Facebook news posts, including the value of news factors discussed in Study 1. Answer categories and statements were formulated based on the answers of interviewees of Study 1. Importance was rated on a 5-point Likert scale from 0 "not important at all" to 4 "very important", which was then transformed into scores from 1 to 5 for analysis. 
The level of agreement to statements testing the potential influence of Facebook's News Feed algorithm and Facebook users, professional journalistic standards, the news brand, and audience metrics on posting decisions derived from the qualitative interviews of Study 1. An oblimin rotated principal component analysis suggests a three-component solution for these external and internal determinants of posting decisions accounting for $71 \%$ of variance and correlating with $r=-.157$ (component 1 and 2) and $r=.138$ (component 2 and 3). Three statements “My Facebook posts aim at 'pleasing' Facebook's News Feed algorithm," "My Facebook posts aim at 'pleasing' Facebook users," and "Our Facebook posts represent what users want to know" comprise one component (Cronbach's alpha .623), which was summarized to a mean index representing platform influences in news making ("Facebook's algorithm \& users"). "Our news brand guides what I post on Facebook" and "Professional journalistic standards guide what I post on Facebook" result in another component of traditional influence with a Cronbach's alpha of .264 , which was therefore not summarized to an index. "Audience metrics steer my posting decisions" comprises a third component.

The importance of news factors for Facebook news compared to website news were asked on a 5-point Likert scale from -2 "much less important" to +2 "much more important". The frequency of news beats (current affairs, foreign and domestic politics, economy, crime and law, culture, sports, health, and entertainment, see Worlds of Journalism Study, 2007) compared to the website was indicated on a 5-point Likert scale from -2 "much less often" to +2 "much more often". This was then transformed into 
scores of 1 to 5 for analysis. News factors and news topics were displayed in a random order. Professional background, job title, age, gender, and news organization of the social media editors were collected.

The time required to answer the survey was 16 minutes on average. Job titles of respondents were social media editor, social media journalist, head of audience dialogue, social media producer, head of social media and online, and community developer. The news outlet diversity was low within the Finnish sample with $n=11$ respondents from the PSB Yle. In Switzerland, five respondents worked at the PSB SRF, four at the publishing house Tamedia, four at NZZ, three at the publishing house Ringer, and two at an independent weekly news magazine. The most common background was online journalism (77\%), followed by print (34\%) and broadcast journalism (26\%). On average, editors were 34 years old (standard deviation [SD] 8.59), had 3 years of experience (SD 2.19) as social media editors, and $43 \%$ were female. Overall, social media editors evaluate their social media skills as very good (mean 4.7, SD 0.53).

\section{Results}

\section{Functions of social media}

According to the interviews, social media channels allow a greater reach, which is why Facebook with its general audience is the most important social media channel for most news outlets. The Yle social media editor emphasizes that younger audiences can 
be reached via Facebook, which is an important strategic goal of Yle. For SRF News, Twitter is more important because it aims to reaching opinion leaders. To reach opinion leaders is also important for Taloussanomat. Obtaining traffic on their own websites is more strongly emphasized by social media editors of the commercial news outlets. The Yle social media editor reports that audience engagement is more important than traffic, "It's not our main target to get the clicks but it's nice when you do. [...] But we have the engagement on our social media board score. [...] Engagement is such a big thing." As a consequence of engagement, Taloussanomat refers to relationship-building opportunities through social media: "Our goal is to have as many engaged people in different social media [contexts] in order to build a relationship and have people that want to come back."

Social media is also used as a "door to the audience" (NZZ). Editors of Taloussanomat, SRF News, and NZZ emphasize the "issue seismograph" function of social media; i.e., researching for current topics and understanding how those topics are discussed to inspire editorial work and foster a dialogue with the audience. Social media is also partly employed to get qualitative feedback, information, and content from users.

Survey results confirm that Facebook is regarded as the most important social media channel (mean 4.9, SD 0.24), followed by Instagram (mean 4.2, SD 0.68) and Twitter (mean 4.0, SD 0.92). Twitter is rated as more important $(t$-test, $p<0.05)$ by Swiss than Finnish social media editors, which may be caused by higher Twitter usage numbers in Switzerland than in Finland. YouTube, WhatsApp and Snapchat were rated between somewhat to minimally important. Regarding the functions of these social media channels, 
the ability to tie users to the news outlet was regarded most important (mean 4.7, SD 0.66), followed by reaching new users (mean 4.5, SD 0.66), enhancing relationships with users (mean 4.5, SD 0.66), reaching young users (mean 4.2, SD 0.97), building a user community (mean 4.1, SD 0.87), and learning about relevant issues from users (mean 4.0, SD 0.92). The Finnish social media editors rated reaching young users as more important than Swiss ( $t$-test, $p<0.05)$, which may be caused by the large share of Yle respondents in the Finnish sample. Correspondingly, engagement measures such as session time, scroll depth or time spent (mean 4.5, SD 0.89), reach measures such as unique users or page impressions (mean 4.2, SD 0.97), loyalty measures such as return visits (mean 4.2, SD 0.89), and social media shares (mean 4.1, SD 0.85) are the most important audience metrics observed in the editorial offices. Comments (mean 3.6, SD .92) and social media likes (mean 3.4, SD .88) are somewhat less relevant.

Overall, social media editors foremost value the loyalty, reach, and engagement potential of social media, especially of Facebook. Besides, social media is an issue seismograph that is helpful for understanding topics that audiences are interested in.

\section{Facebook's News Feed algorithm and Facebook users}

The interviewed editors indicate that the ability to maximize audience engagement and reach on Facebook depends on their knowledge about the Facebook algorithm. Editors explain that they have gained some intuition about how the Facebook algorithm 
operates through observing audience behavior: "I know how the Facebook algorithm works since I have been posting on Facebook for a long time. I live the Facebook life. I watch the analytics all the time" (Yle). The algorithm is considered as an autonomous but diffuse actor. The NZZ social media editor highlights that they strive to post sharable content on Facebook to "please the algorithm". The Yle social media editor describes the actions of the algorithm with "the algorithm makes [news posts] show up on people's news feed. I don't know. If you use a word or something. It finds the audience if it's good.” Yet it remains unclear how the algorithm selects content and the editors make low effort to comprehend this process because it appears to be ever-changing. The Taloussanomat social media editor complains about the obscurity of the Facebook algorithm: "It's not transparent at all and really hard to describe. Frustrating [... They change it every time. Suddenly, the traffic that you get from Facebook drops to zero when they tweaked their algorithms." Therefore, the editor concludes, "It is a bit useless to invest too much time in cracking the algorithm." The Watson social media editor agrees that it is not important to know all about the Facebook algorithm because it changes unpredictably, but experimenting is more fruitful.

Therefore, efficient social media news making is somewhat hindered by the obscure functions of the Facebook algorithm, which social media editors try to overcome by maximizing their experience with user behavior on Facebook.

The survey confirms that social media editors agree on the importance to understand how the Facebook News Feed algorithm works (mean 4.9, SD 0.46), but they 
agree to a lesser extent that they understand how it works (mean 3.8, SD 0.88). Instead, they comprehend what kind of content Facebook users engage with (mean 4.4, SD 0.56) and aim at "pleasing" Facebook users (mean 4.3, SD 0.70) rather than "pleasing" the Facebook algorithm (mean 3.3, SD 1.20). Social media editors neither agree nor disagree that the News Feed algorithm selects content that they consider as irrelevant for users (mean 2.9, SD 1.01).

Thus, the visible and measurable user behavior is what determines social media news making directly whereas the ever-changing algorithm remains obscure.

\section{News values, professional standards, and the news brand}

In the interviews, social media editors distinguish between news selection, that is, picking a story from the news outlet's website or, more rarely, producing content exclusively for social media, and news editing, that is, accentuating certain aspects of a chosen story in its Facebook post.

Social media editors emphasize that the selection of social media news is conducted traditionally according to what the audience ought to know, which is partly supported by engagement metrics. The Taloussanomat social media editor explains their news selection process:

First, we decide what is newsworthy. When it's ready, we publish it on our own page. [...] We look at how many readers engage in an article within 2 minutes. 
After 4 minutes, we can tell that the story has much more potential. Then we decide if an article is interesting for our Facebook or Twitter audience. (Taloussanomat)

Social media news editing is allowed to deviate somewhat from traditional standards. This is reflected in a distinct set of news values that determine which story elements social media editors emphasize on Facebook. Interviewed social media editors find emotions, surprise, oddity, and social impact most important for successful Facebook posts. The engaging effect of emotions is highlighted by all social media editors. The SRF News editor reports that emotional topics have a greater tendency to go viral. Helsingin Sanomat tries to appeal to emotions. To get engagement, "you have to raise some kind of feelings. If you say, 'read more on our website,' people won't do that. It has to awake curiosity, for example." (Yle). The NZZ as well as the Yle social media editors stress success and positive consequences as their users interact with good news that reveal a happy ending. These news values help the editors to "carve out the social media essence" of a story (NZZ). Such news does not have to be related to current political or economic news but could be a story like "boy saved dog." The Yle social media editor observed, "Usually, there are some kind of phenomena, like heroic stories. It's not the government talks that are the most engaging stories".

The surveyed social media editors state that professional journalistic standards (mean 4.4, SD 0.78) as well as audience metrics (mean 4.5, SD 0.71) guide their news selection decisions. Both, journalistic standards and audience metrics are more important 
for Finnish (mean 4.7, SD 0.46 and 4.8, SD 0.43, respectively) than Swiss social media editors (mean 4.2, SD 0.89 and 4.3, SD 0.79) ( $t$-test, $p<0.05$ ). Based on one-sample $t$ tests against the middle of the scale (3), survey results show that the news factors emotions (mean 4.6, SD 0.66), surprise (mean 4.3, SD 0.73), success (mean 3.9, SD 0.92), geographical proximity (mean 3.7, SD 1.0), conflict (mean 3.7, SD 0.90), social impact (mean 3.6, SD 0.70), prominence (mean 3.5, SD 1.00), and opinion (mean 3.4, SD 0.98) are more important for news to be posted Facebook compared to website news $(p<0.05)$ (see Figure 1). Facts (mean 3.4, SD 1.05), damage or negative consequences (mean 3.2, SD .71), and power (mean 3.0, SD 0.95) are similarly important for Finnish social media editors. For Swiss social media editors, damage or negative consequences and power are more important $(t$-test, $p<.05)$. Criminality (mean 2.39, SD 0.72) is a less important news factor for Facebook news compared to website news. Success or positive consequences is valued more greatly by Finnish than Swiss editors (mean 4.3, SD 0.75, $\mathrm{n}=14$; mean 3.6, $\mathrm{SD} 0.96, \mathrm{n}=20, t$-test, $p<0.05)$.

[Figure 1 about here]

In the interviews, the discussion about news values is highly interwoven with journalistic standards and news brand characteristics. Regarding the news brand, Watson (the "younger", online-only outlet) and NZZ (the traditional hard news outlet in Switzerland) state that the news focus of their brand has to reflect their social media postings. 
If we adapted our topics to the social media crowd, we would report just good news. However, the audience should learn from news. We also cannot switch into colloquial mode such as Watson could do. [...] We try to use a more casual tone for social media but consider the NZZ personality. (NZZ)

Although balanced, informative news does not work well, the Watson profile has to be represented on Facebook. We cannot post just viral content. (Watson)

Similarly, Taloussanomat states that their core business and not social networks remain their focus, "We have to concentrate on what we can do best and if there's something for us being on Facebook." Although the Taloussanomat social media editor does not explicitly mention the brand, their specific news focus is emphasized. Regarding journalistic standards, the SRF News social media editor finds transparency and factual accuracy important because it helps retain a trusted relationship with readers: "We need transparency throughout the whole journalistic process. How and why we report about something. Because news is trust-based." The Helsingin Sanomat social media editor similarly states that impartiality is very important and "as important as anywhere else."

According to the survey, the news brand is a mediocrely important guide for the Facebook posts of Swiss social media editors (mean 3.4, SD 1.2, $\mathrm{n}=20$ ) but it is highly relevant for the posts of Finnish respondents (mean 4.9, SD 0.36, $\mathrm{n}=15)(t$-test, $p<0.05)$. 


\section{Social media news content}

The interviewed social media editors have a clear understanding about suitable topics for social media. Watson declares that informative news does not work well, "hard news that are not a huge scandal, natural disaster or terrorist attack, always work badly" for their younger audience. According to Watson, political news for example have to be related to individual fates to be shared and liked rather than to the bare facts. Regarding editing, Yle's social media editor suggests that Facebook posts can have a stance because “if you're both black and white on the posts, it won't help anyone. But still you have to try to be neutral because we are a public-service company. So at least in the story on our site, we need to have the other side."

SRF as well as NZZ stress that the goal is to represent the news of the day. Thus, a balance between soft and viral news as well as hard news has to be found in accordance with the news brand. Taloussanomat uses Facebook for general, everyday life news, such as "personal finance, housing, investing own money, cars, petrol prices. On Twitter, we go into the deep-end of financial journalism, like stock moves or major transactions." The Yle social media editor states that the audience should not be overloaded with political news on social media.

People get so bored of political news. [...] because you have the same prime minister, you have the same names, and people just don't see the difference anymore. If we have too much of the same, the reach goes down. (Yle) 
According to the survey, health (mean 3.5, SD 0.97) and entertainment news (mean 3.4, SD 0.97) is posted somewhat more often on Facebook than on the website (onesample $t$-test against the middle of the scale $(3), p<0.05)$. Whereas foreign politics (mean 2.5, SD 0.95) and economic news (mean 2.5, SD 0.76), in addition to domestic politics (only in Finland) (mean 2.5, SD 0.85, $\mathrm{n}=15$ ), is posted less often. News/current affairs, culture, crime and law, sports, and, only in Switzerland, domestic politics is posted as frequently as it is on the website. However, the mean values for health and entertainment news as well as foreign politics and economic news suggest that the differences in news on the websites should not be extreme.

Overall, although social media editors strive to inform their social media audience well according to traditional journalistic standards, they regard lightweight news topics or hard news that is given lightweight characteristics through editing to be more appropriate for social media.

\section{Determinants of social media news content}

The effects of news outlet's internal and external determinants of social media news making are tested with linear regressions for four types of content: health, entertainment, economic, and foreign politics. The former two are posted more often and the latter two less often on Facebook compared to the news outlet's website. 
Results reveal that the more social media editors aim to please the Facebook algorithm and Facebook users, the higher is the level of entertaining news on Facebook compared to the website (see Table 1). Although economic news is shared less often on Facebook, the more social media editors are guided by professional journalistic standards, the higher is the amount of economic news on Facebook. The analysis finds no relationship between the news brand and audience metrics for the four news content types. None of the tested external or internal influences can explain the higher level of health news and lower level of foreign news on Facebook compared to the news on the outlet's website.

[Table 1 about here]

\section{Discussion and limitations}

The social media editors in this study may be described as "enthusiastic social media activists" (Hedman and Djerf-Pierre, 2013), who live a social media life and develop a distinctive professional culture and procedures. But they are also tied to traditional professional norms and are skeptical about the obscurity of Facebook's News Feed algorithm.

Social media editors partly adapt to the logic of the engagement-rewarding social media algorithms as they strive to select and edit news in a way that it maximizes engagement. For social media editors, the requirements of the social media algorithm 
become evident in user behavior. User behavior comprises one dimension of News Feed algorithm content selection criteria (DeVito, 2017). Whereas the algorithm selection process remains obscure for social media editors, they understand user behavior and adapt news accordingly, which is the second dimension of algorithm selection criteria (DeVito, 2017). That is, user behavior serves as input information for both the News Feed algorithm and social media editors. Social media editors then adapt news content to match user preferences, which serves as second input information for the algorithmic content selection. Thereby, the social media news making process optimizes content for algorithmic selection.

When editing news, social media editors value engagement-rewarding news values higher, which confirms Wasike's (2013) assumption that social media editors hold unique news values. News is edited in a way that it arouses emotions and has a large social impact. The higher values of emotions, surprise, success, geographical proximity, conflict, social impact, prominence, and opinion for Facebook news compared to website news are in line with previous results showing a positive relation between these news factors and user engagement (Berger and Milkman, 2012; Tenenboim and Cohen, 2015; Weber, 2014). Facts and the power of the protagonist are not more important for social media editors, which can be explained with Weber's (2014) findings that these news factors decrease user engagement. Yet despite an ongoing public discussion of misinformation and fake news distribution on Facebook, social media editors do not regard the news factor facts 
as more important for Facebook news than for website news, which may be due to a widely absence of the problem of misinformation in both countries.

However, the present results do not suggest a radical breach with traditional news factors in favor of a personal instead of social significance of news, as suggested by DeVito (2017). First, social media editors regard traditional news factors relating to deviance and social significance as relevant on Facebook. Second, the news brand and traditional journalistic standards guide social media editors' news making decisions. Both function as counterweights to an excessive alignment to user preferences and partly hinder the shift towards lightweight news. Although both are linked value systems (Sylvie, 2007), journalistic standards are found to be more powerful than the news brand for social media news making. A stronger orientation towards journalistic standards accounts for a higher level of economic news on Facebook in this study. In contrast, a stronger orientation towards Facebook's News Feed algorithm and user preferences is related to a higher level of entertaining news. This is in line with Craig and Yousuf (2013), who report that sophistication in engagement and traditional standards are important for social media news making. Yet whether the influence of traditional standards may fade is unclear.

The orientation towards traditional journalistic standards stems from the journalistic background of the social media editors, which is relevant for their socialization (Gravengaard and Rimestad, 2014). Yet there are new socializing factors in social media news making. Similar to the findings described by Craig and Yousuf (2013) and Papacharissi (2014), the social media editors in this study implicitly learned how to 
successfully post on social media through practice. In parallel, they learned about the social media algorithms and user behavior. With advancing practice, knowledge and routine increase over time, which may result in news content being selected and edited in a more social media-appropriate fashion over time. Thus, the effects of the social media algorithm logics and user behavior on social media news making and news may intensify over time, which is suggested by results of a longitudinal content analysis of social media news (Lischka and Werning, 2017). Future research may focus on observing how professional standards, working procedures, and news values of social media editors develop over time and how this relates to news supply on social media, as well as whether social media editors retain a journalistic background.

Major limitations to the present study are the small sample size, especially regarding the regression analysis, the sample structure, and the focus on two specific media markets. Hence, results cannot be transferred to large media markets with a greater audience potential or where social media platforms are more frequently used news sources, and to news outlets that have been using social media for a very long period. In such conditions, social media news making may follow standards and routines that more strongly differ from online news making than found in the present study. In addition, differences in the importance of the news brand and traditional standards exist between Finnish and Swiss social-media editors, which may be due to the larger share of PSB social media editors in the Finnish sample. Furthermore, the present findings mostly relate to the Facebook News Feed ranking algorithm. Results may differ for other social media 
channels because of different user behaviors and preferences, in addition to less routinized working procedures. Finally, the actual posted content of the news outlets of the interviewed and surveyed social media editors has not been analyzed.

\section{Conclusions}

This study draws conclusions regarding the social media news making process and the resulting news supply on Facebook. First, the demands of Facebook's News Feed algorithm, its users, the news brand, and journalistic professional standards are contradictory forces determining the news output of hard news outlets on Facebook. For social media editors, the engagement-rewarding algorithm becomes observable through user behavior, which triggers the selection of rather lightweight news and an editing of posts that lead to user engagement. The results of this study suggest that posted news favor entertaining topics to the disadvantage of international politics and economic news. Social media editors accentuate those elements in a story that fulfil the news values of emotions, surprise, and social impact. This confirms the findings of $\mathrm{Vu}$ (2014) and Andersson and Wadbring (2015) that news values of social media editors are userengagement and algorithm driven.

However, social media editors do not radically breach with traditional news factors as sometimes suspected (DeVito, 2017; Dimitrov, 2014; Hedman and Djerf-Pierre, 2013). The news brand and professional standards are hard to change fundamentally (Ekdale et 
al., 2015; Ryfe, 2009; Siegert et al., 2011) and set boundaries to a heavy engagement focus. A higher orientation toward journalistic standards is related to a higher level of economic news in the present study. Like Karlsson and Clerwall (2013) conclude for online journalists, also social media editors strive for a "good mix" of news topics adhering to user demands and professional journalistic standards. The socialization of social media editors may play an important role in valuing professional journalistic standards in a social media environment.

Although social media platforms provide news outlets with the opportunity to reach audiences that may not be reached through other distribution channels, the informational benefits to social media users may be lower because of an increased amount of entertaining news and a reduced amount of foreign politics and economic news. This is related to the question of whether a media system aiming at serving the informational needs of its citizens can sufficiently serve social media users in the context of engagement-rewarding algorithms. Particularly, social media news cannot increase political knowledge of users that often hold a passive news-will-find-me perception (Gil de Zúñiga et al., 2017). From a welfare perspective, the informational needs of audiences consuming news exclusively through social media may not be satisfied in order to make well-informed political and economic decisions. Although the social media news supply serves informational needs to a basic degree, it prioritizes the entertainment preferences of the users. Hence, "audience segments most in need of the informational and educational benefits of newspaper readership" (Napoli, 2006: 285) are not informed 
sufficiently. Against the background of Facebook's announcement to deprioritize content from brands, including news, in favor of friends' posts, information supply on users' news feeds will worsen. News providers will refocus on a distribution strategy that complies with the new logic of the News Feed algorithm or fundamentally rethink their social media strategy, including Facebook's value for news distribution. In this regard, Oremus (2018)expects that news providers enter a new era in which Google, AppleNews, and

Twitter account for more traffic than Facebook.

\section{References}

Andersson U and Wadbring I (2015) Public interest or self-interest? How journalism attracts future journalists. Journal of Media Practice 16(2): 126-138.

Berger J and Milkman KL (2012) What makes online content viral? Journal of Marketing Research 49(2): 192-205.

Brüggemann M, Engesser S, Büchel F, Humprecht E and Castro L (2014) Hallin and Mancini Revisited: Four Empirical Types of Western Media Systems. Journal of Communication 64(6): 1037-1065.

Bundesamt für Statistik (2014) Internetnutzung in den Schweizer Haushalten 2014: Die sozialen Netzwerke - nicht nur eine Sache der Jugendlichen. Available at: http://www.bfs.admin.ch/bfs/portal/de/index/news/medienmitteilungen.html?pressID=9887

Chan-Olmsted SM (2011) Media branding in a changing world: Challenges and opportunities 2.0. International Journal on Media Management 13(1): 3-19.

Cherubini F and Nielsen RK (2016) Editorial Analytics: How News Media Are Developing and Using Audience Data and Metrics. Available at: http://www.digitalnewsreport.org/publications/2016/editorial-analytics-2016/.

Craig DA and Yousuf M (2013) Excellence in journalistic use of social media through the eyes of social media editors. \#ISOJ 3(2): 93-111.

DeVito MA (2017) From editors to algorithms. Digital Journalism 5(6): 753-773.

Dimitrov R (2014) Do social media spell the end of journalism as a profession? Global Media Journal: Australian Edition 8(1): 1-16. 
Ekdale B, Singer JB, Tully M and Harmsen S (2015) Making Change: Diffusion of Technological, Relational, and Cultural Innovation in the Newsroom. Journalism \& Mass Communication Quarterly 92(4): 938-958.

Facebook Inc (2015) FORM 10-K: (Annual report). Available at: http://investor.fb.com/secfiling.cfm?filingID=1326801-15-6\&CIK=1326801 (accessed 22 August 2015).

Gade PJ (2004) Newspapers and organizational development: Management and journalist perceptions of newsroom cultural change. Journalism \& Communication Monographs 6(1): 355.

Gil de Zúñiga H, Weeks B and Ardèvol-Abreu A (2017) Effects of the News-Finds-Me Perception in Communication: Social Media Use Implications for News Seeking and Learning About Politics. Journal of Computer-Mediated Communication 22(3): 105-123.

Gillis TL and Johnson K (2015) Younger journalists more likely to use social media. Newspaper Research Journal 36(2): 184-196.

Gravengaard G and Rimestad L (2014) Socializing journalist trainees in the newsroom. Nordicom Review 35: 81-95.

Groot Kormelink T and Costera Meijer I (2014) Truthful or engaging? Digital Journalism 3(2): 158-174.

Hallin DC and Mancini P (2004) Comparing media systems: Three models of media and politics. Cambridge: Cambridge University Press.

Hedman U and Djerf-Pierre M (2013) The social journalist: Embracing the social media life or creating a new digital divide? Digital Journalism 1(3): 368-385.

Karlsson M and Clerwall C (2013) Negotiating professional news judgment and "clicks". Nordicom Review 34(2): 65-76.

Krebs I and Lischka JA (2017) Is audience engagement worth the buzz?: The value of audience engagement, comment reading, and content for online news brands. Journalism.

Latzer M, Just N, Metreveli S and Saurwein F (2013) Internet-Anwendungen und deren Nutzung in der Schweiz 2013: Themenbericht aus dem World Internet Project-Switzerland 2013. Available at: http://www.mediachange.ch/media/pdf/publications/Anwendungen_Nutzung_2013.pdf (accessed 3 June 2015).

Lischka JA, Siegert G and Krebs I (2018) Marketing and Branding. In: Albarran AB, Mierzejewska B and Jung J (eds) Handbook of media management and economics. New York, NY: Routledge.

Lischka JA and Werning M (2017) Wie Facebook den Regionaljournalismus verändert: Publikums- und Algorithmusorientierung bei der Facebook-Themenselektion von Regionalzeitungen. Algorithmen, Kommunikation und Gesellschaft. Sonderausgabe von kommunikation@gesellschaft. kommunikation@gesellschaft 18: 1-25.

McManus JH (1994) Market-driven journalism: Let the citizen beware? Thousand Oaks, CA: Sage. Napoli PM (2006) Issues in media management and the public interest. In: Albarran AB, ChanOlmsted SM and Wirth MO (eds) Handbook of media management and economics. Mahwah, NJ: Lawrence Erlbaum, pp. 275-295. 
Neuberger C, Langenohl S and Nuernbergk C (2014) Social Media und Journalismus. Düsseldorf: Landesanst. für Medien Nordrhein-Westfalen (LfM).

Newman N, Fletcher R, Levy DAL and Nielsen RK (2016) Reuters Institute digital news report 2016. Available at: http://www.digitalnewsreport.org/ (accessed 29 June 2016).

Nummela T (no year) SuomiTwitter: Calculating Finnish tweeps since February 7th 2013. Available at: http://www.toninummela.com/suomi-twitter/.

Oremus W (2018) The Great Facebook Crash. slate.com, 27 June.

Papacharissi Z (2014) Toward new journalism(s). Journalism Studies 16(1): 27-40.

Ryfe DM (2009) Broader and deeper: A study of newsroom culture in a time of change. Journalism 10(2): 197-216.

Scacco J, Curry AL and Stroud NJ (2015) Digital divisions: Organizational gatekeeping practices in the context of online news. \#ISOJ 5(1): 106-123.

Siegert G, Gerth MA and Rademacher P (2011) Brand identity-driven decision making by journalists and media managers: The MBAC model as a theoretical framework. International Journal on Media Management 13(1): 53-70.

Statistics Finland (2014) One half of Finnish residents participate in social network services. Available at: http://www.stat.fi/til/sutivi/2014/sutivi_2014_2014-11-06_tie_001_en.html (accessed 28 August 2015).

Steiner M (2016) Boulevardisierung goes Facebook?: Ein inhaltsanalytischer Vergleich politischer Nachrichten von tagesschau, heute, RTL Aktuell und Sat.1 Nachrichten im Fernsehen und auf Facebook. In: Leißner L, Bause H and Hagemeyer L (eds) Politische Kommunikation - neue Phänomene, neue Perspektiven, neue Methoden. Düsseldorfer Forum Politische Kommunikation DFPK 6. Berlin: Frank \& Timme, pp. 27-46.

Sylvie G (2007) Decision making by nordic newspaper editors: An exploratory study and comparison to US editors. Jönköping: Jönköping International Business School.

Tenenboim O and Cohen AA (2015) What prompts users to click and comment: A longitudinal study of online news. Journalism 16(2): 198-217.

Usher N (2014) Making news at the New York Times. Ann Arbor, MI: University of Michigan Press.

Vu HT (2014) The online audience as gatekeeper: The influence of reader metrics on news editorial selection. Journalism 15(8): 1094-1110.

Wasike BS (2013) Framing news in 140 characters: How social media editors frame the news and interact with audiences via Twitter. Global Media Journal: Canadian Edition 6(1): 5-23.

Weber P (2014) Discussions in the comments section: Factors influencing participation and interactivity in online newspapers' reader comments. New Media \& Society 16(6): 941-957.

Worlds of Journalism Study (2007) Master questionnaire: journalists. Available at: http://www.worldsofjournalism.org/docs/Master\%20questionnaire\%20journalists\%20EN\%2 0final.pdf (accessed 17 February 2014). 
ACCEPTED VERSION: LOGICS IN SOCIAL MEDIA NEWS MAKING

Lischka, J. A. (2018). Logics in Social Media News Making: How social media editors marry the Facebook logic with journalistic standards. Journalism, Advance online publication.

https://doi.org/10.1177/1464884918788472

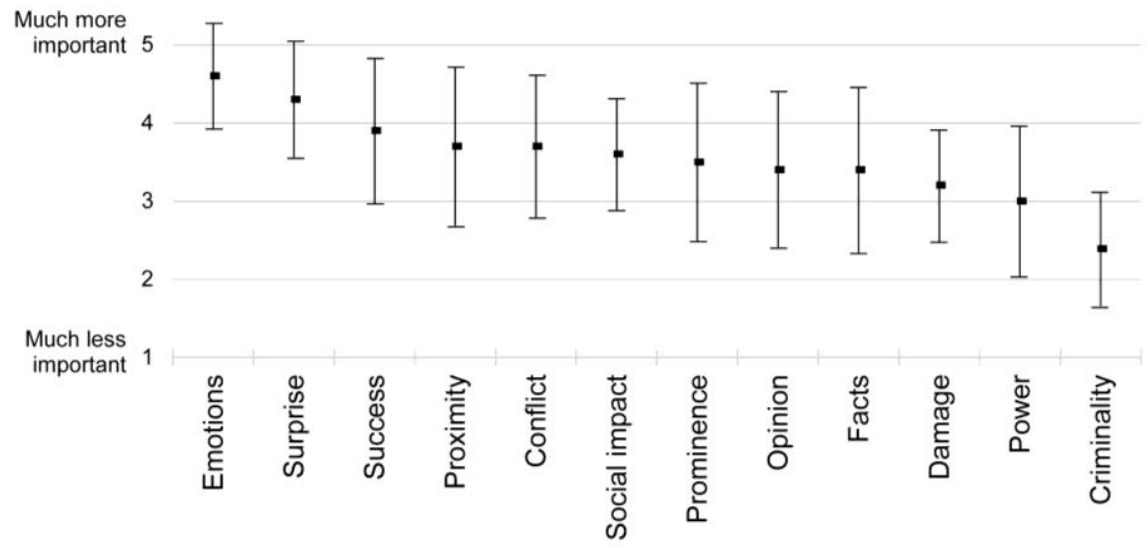

Figure 1: News values of social media editors

Note: Results for $\mathrm{n}=35$ Finnish and Swiss social media editors. Mean and standard deviation. Importance for news on Facebook compared to website news. 
ACCEPTED VERSION: LOGICS IN SOCIAL MEDIA NEWS MAKING

Lischka, J. A. (2018). Logics in Social Media News Making: How social media editors marry the Facebook logic with journalistic standards. Journalism, Advance online publication.

https://doi.org/10.1177/1464884918788472

Table 1: Influences on popular and less popular social media news topics

\begin{tabular}{|c|c|c|c|c|}
\hline & Entertainment & Health & Economy & Foreign politics \\
\hline & $\mathrm{B}(\mathrm{SE})$ & $\mathrm{B}(\mathrm{SE})$ & $\mathrm{B}(\mathrm{SE})$ & $\mathrm{B}(\mathrm{SE})$ \\
\hline Facebook's & $0.612^{*}$ & 0.251 & -0.195 & -0.178 \\
\hline algorithm \& users & $(0.236)$ & $(0.212)$ & $(0.178)$ & $(0.311)$ \\
\hline Journalistic & -0.058 & 0.429 & $0.250 *$ & -0.148 \\
\hline standards & $(0.258)$ & $(0.343)$ & $(0.100)$ & $(0.372)$ \\
\hline \multirow[t]{2}{*}{ News brand } & -.034 & 0.153 & -0.065 & -0.135 \\
\hline & $(0.158)$ & $(0.170)$ & $(0.083)$ & $(0.194)$ \\
\hline \multirow[t]{2}{*}{ Audience metrics } & -0.014 & 0.191 & 0.203 & 0.080 \\
\hline & $(0.159)$ & $(0.131)$ & $(0.109)$ & $(0.152)$ \\
\hline \multirow[t]{2}{*}{ Constant } & 1.697 & -0.523 & 1.699 & 4.176 \\
\hline & $(1.883)$ & $(1.728)$ & $(0.939)$ & $(2.110)$ \\
\hline \multirow[t]{2}{*}{$F(p)$} & 1.889 & 2.043 & 2.525 & .427 \\
\hline & $(.142)$ & $(.118)$ & $(.129)$ & $(.788)$ \\
\hline Adj. $R^{2}$ & .106 & .077 & .169 & -.086 \\
\hline Durbin-Watson & 1.813 & 2.312 & 1.739 & 1.761 \\
\hline $\mathrm{n}$ & 31 & 31 & 31 & 30 \\
\hline
\end{tabular}

Note: Ordinary-least squares regression. Standard errors (SE) based on 1000 bootstrap samples. ${ }^{*} p<.05$. Popular Facebook news topics: Entertainment and health; less popular: Economy and foreign politics. 